\title{
A inscrição da educação como direito social no Brasil: uma história viciada
}

\author{
The inscription of education as a social right in Brazil: an addicted history
}

\section{L'inscription de l'éducation comme droit social au Brésil: une histoire de toxicomanie}

Flávio Bezerra de Sousa ${ }^{1}$ Universidade Estadual de Campinas

\begin{abstract}
Resumo: O presente artigo apresenta um debate em torno da conceituação histórica de cidadania e a inscrição da educação como direito social. Tem como objetivo apreciar os elementos explicativos de inscrição desse conceito e seus desdobramentos no âmbito das políticas educacionais, especialmente sob a égide dos interesses da Nova Gestão Pública (NGP). O trabalho tem como configuração conceitual a pesquisa bibliográfica e de contexto. Desta forma, buscou-se delinear apontamentos que auxiliam na compreensão de como ocorreu o estabelecimento das políticas educacionais no Brasil, e de como ela está amparada pelas conceituações em torno do direito à educação como elemento sustentador da política pública, mas que é afetada por interesses instados no cronograma da lógica de mercado.
\end{abstract}

Palavras-chave: Cidadania. Direito Social. Estado e Políticas de Educação. Nova Gestão Pública.

Abstract: This article presents a debate about the historical conceptualization of citizenship and the inscription of education as a social right. It aims to appreciate the explanatory elements of the inscription of this concept and its consequences in the context of educational policies, especially under the aegis of the interests of New Public Management (NGP). The work has as conceptual configuration the bibliographical and contextual research. Thus, we sought to outline notes that help understand how the establishment of educational policies in Brazil, and how it is supported by the conceptualizations around the right to education as a supporting element of public policy, but which is affected by interests in the timeline of market logic.

Keywords: Citizenship. Social law. State and Education Policies. New Public Management.

Résumé: L'article présente un débat sur la conceptualisation historique de la citoyenneté et l'inscription de l'éducation comme droit social. Il vise à apprécier les éléments explicatifs de l'inscription de ce concept et ses conséquences dans le cadre des politiques éducatives, notamment sous l'égide des intérêts du New Public Management (NGP). L'ouvrage a pour configuration conceptuelle la recherche bibliographique et contextuelle. Ainsi, nous avons cherché à esquisser des notes qui aident à comprendre comment la mise en place de politiques éducatives au Brésil, et comment elle est soutenue par les conceptualisations autour du droit à l'éducation en tant qu'élément de soutien des politiques publiques, mais qui est affecté par les intérêts dans la chronologie de la logique du marché.

Mots-clés: La citoyenneté. Droit social. Politiques de l'État et de l'éducation. Nouvelle Gestion Publique.

\footnotetext{
1 Doutorando em Estado, Políticas Públicas e Educação do Programa de Pós-Graduação em Educação da Universidade Estadual de Campinas. E-mail's: f229644@dac.unicamp.br, saintflavio35@gmail.com. ORCID: https://orcid.org/0000-0002-1655-7220. Lattes: http:// lattes.cnpq.br/9361237803540346.
} 


\section{Indrodução}

O cenário é de enfrentamento dos desafios postos à chamada democracia no "Estado Burguês", especialmente o que insere o direito como um dos elementos que sustentam sua base de existência.

Garantir direitos na contemporaneidade significa, diante de um conjunto de processos conflitantes na sociedade de classes, transpor barreiras provocadas, principalmente, pelo modo de produção capitalista que cada vez mais se propõe a minimizar ou ocultar o seu significado e impacto ao prazer de uma nova sociedade requerida, cuja flexibilidade no campo do trabalho, e a disposição da educação como serviço a ser prestado, sustenta uma lógica de dominação na busca do consenso, no estabelecimento de uma hegemonia social que se cria e se reveste nas nuances dos espaços sociais sem ser vista, mas sentida na sua forma de atuar, e que assim estabelece um campo consolidado e tardio para o enfrentamento, se não por uma educação comprometida.

No momento em que a cidadania enfrenta novos desafios, busca novos espaços e abre novas áreas por meio das grandes transformações pelas quais passa o mundo contemporâneo, como aponta Cury (2000), é de suma importância ter o conhecimento de diversas realidades que, no passado, significaram, e assim se põe até hoje, passos relevantes no sentido da garantia de um futuro melhor para todas e todos.

Os processos educativos estiveram permeados, ao longo da história, pelos fluxos de conformação de sociedade no que viria ser Estado. Nesse sentido, a educação é tomada por uma valoração de sua capacidade de influir e conformar aspectos sociais, mas que, por meio deles, torna-se um propicioso instrumento de sobreposição de ideias, discursos e consensos, além de sua instrumentalização para a perspectiva formativa que o modo de produção capitalista se dispõe a obter para fins de manutenção do statos quo.

A educação, vista sob a ótica de um fluxo contrário à corrente precisa ratificar o seu papel transformador e sair da mera esfera do resultado do mundo do trabalho capitalista, principalmente àquele que visa o seu uso de preparação ao trabalho simples. A sua relação com o capital, trabalho e Estado precisa ser superada para além de um instrumento de uso que será conduzido para uma prisão do valor de troca por parte do trabalhador, para de fato exercer papel emancipador do sujeito.

Desde sempre a educação esteve ancorada, se não escamoteada, ao subterfúgio da formação de sujeitos como resposta à demanda da sociedade alocada na pesrpectiva de Estado, 
mas, sua essência deve colocá-la como elemento punjante de transformação social, principalmente, aquela posta afim de romper com os processos sociometabólicos ${ }^{2}$ presentes na hierarquização das relações de trabalho como pontua István Mészáros (2011) em suas reflexões.

Nesse sentido, quais papeis ela deve desempenhar numa sociedade tão marcada pelos interesses e ditames de um sistema? Como a educação se insere enquanto elemento da cidadania, por via da garantia do direito, no Estado burguês? O seu percurso enquanto direito de fato responde às demandas da sociedade, ou apenas ratifica as intencionalidades do Estado capitalista, principalmente quando este se reveste em sinuosos contraposicionamentos sociais?

Para a discussão ${ }^{3}$, se propõe um caminhar sobre o conceito e as características de cidadania no Estado moderno, principalmente marcada pela sua evolução no campo do direito como via de cumprimento e supressão dos interesses de classes. Em seguida, faz-se salutar uma caminhada histórica do surgimento da educação como direito social e como ela está inserida à luz do ideário do Estado capitalista.

As mudanças provocadas pela Nova Gestão Pública (NGP) ${ }^{4}$ como instrumento de persuasão circunscrita ao direito à educação é o terceiro ponto de debate e se caracteriza como o momento atual na qual converge o caminhar histórico e problemático apresentado ao campo do direito. Por fim, se propõe uma sinalização de contex to sobre os principais temas em debate no campo das políticas educacionais.

\section{Cidadania: conceitos e características hitóricas que reverberam na educação}

Assentar entendimentos sobre o termo cidadania exige uma reflexão da história já apreendida e registrada pela sociedade. A cidadania pode ser descrita como participação numa comunidade política e na capacidade de participar no exercício do poder como destaca Barbalet (1989).

\footnotetext{
2 Para Mészáros (2011), o sistema de sociometabolismo do capital é o complexo caracterizado pela divisão hierárquica do trabalho, que subordina suas funções vitais ao capital. O capitalismo é uma das formas possíveis da realização do capital, uma de suas variantes históricas, presente na fase caracterizada pela generalização da subsunção real do trabalho ao capital.

3 Não é de interesse, até mesmo pelos limites conceituais e do próprio artigo, dar conta de todos os determinantes existentes, muito menos precisá-los em todos os seus aspectos. A preocupação está em apontar os pontos considerados relevantes para a reflexão que se propõe a desenvolver.

${ }^{4}$ Estudos de Newman \& Clarke (2012), Lima (2014), Paula (2005), Oliveira (2011), apontam a Nova Gestão Pública como um marco de imposião da lógica gerencial na educação, o que, direta ou indiretamente põe em risco a garantia do direito à educação por ser a sua visão pautada em resultados de eficiência no gasto ao contrário de uma perspectiva emancipatória, onde o educando passa ser visto como cliente muito mais do que um cidadão de direitos.
} 
A gênese do termo na sociedade moderna está vinculada à igualdade declarada de todos os cidadãos perante a lei, e que o privilégio no grupo não pode atingir uma pessoa de forma diferenciada. Incide aqui claramente as determinações legalistas que temporalmente sustentou a evolução conceitual do termo cidadania.

Ao nos deparamos com as reflexões de Marshall (1967) sobre cidadania, esta estaria ancorada na evolução temporal do tripé civil, político e social dos direitos a partir das consquistas da classe trabalhadora diante das obrigações emergentes do Estado, conforme sua formação linear estrutural.

$\mathrm{O}$ aspecto civil estabelece forte laço às garantias legais, especialmente sobre aqueles necessários à liberdade individual e que se constitui associada à letra da lei e do sistema judicial, este, preementemente ancorado no imperativo categórico da intangibilidade da vida humana que dá origem aos desígnios do respeito à integridade física e psíquica das pessoas; consideração pelos pressupostos materiais mínimos para o exercício da vida e, respeito às condiçoes mínimas de liberdade e convivência social igualitária (AZEVEDO, 2002).

Ao conceito político se relaciona a ideia da participação no exercício do poder de forma declarada à luz das intecionalidades e desejos do coletivo e, no social, o direito ao nível de vida predominante e ao patrimônio social da sociedade vislumbra-se como possível. Araújo $(2007)^{5}$, ao descrever as características da cidadania, pontua que seu percurso cronológico, indubitavelmente, tem a perspectiva da sociologia inglesa, principalmente aquela que vê seu campo de reflexão sustentado no desenvolvimento do Estado nacional pós revolução industrial.

A necessidade de superação dos privilégios feudais e do absolutismo monárquico, ofereceram condições históricas para a luta pela ampliação dos direitos políticos. E a ampliação desses teria favorecido as demandas da sociedade pela proteção em várias formas.

A sociedade, marcadamente pela caridade, na qual quem dava era quem podia e tinha para isso, em detrimento de quem recebia por que não tinha condições econômicas nenhuma, agora precisava responder no âmbito obrigatório de dever do Estado. A marca fundamental era o conflito de classes que se instaurava diante da cisão ocasionada pelo processo de revolução industrial burguesa.

Contudo, antes de uma melhor compreensão sobre esta sustentação da cidadania no Estado moderno convém alinhar ou entender outros aspectos importantes. O primeiro deles está associado ao momento na qual se antecede a passagem do mundo feudal para o mundo

\footnotetext{
${ }_{5}$ Para Gilda Gardoso Araújo (2007), o campo do direito na cidadania pode assumir as denominações de "programa" como aquilo que se refere ao que é declarado como intenções ou metas e "diagrama” como aquilo que se refere às representações de um dado fenômeno social. A palavra "programa” evoca o sentido de registro das intenções e "diagrama” tras o sentido das respresentações que se fazem desse registro
} 
moderno, em que as relações se pautavam na ação do Estado como exclusivo detentor e promotor de direitos (BOBBIO, 1986). E no Estado despótico, os indivíduos singulares só têm deveres e não direitos, no Estado absoluto, os indivíduos possuem, em relação ao soberano, direitos privados.

Ao iniciar suas reflexões sobre a nova relação do Estado e o extrato da sociedade, Karl Marx (1843) buscou entender o conflito gerado pelo poder normativo e os catadores de lenha da Alemanha,. Nesse estágio de desenvolvimento o Estado exercía, ao escrutínio de classes privilegiadas, o poder de decisão sobre como a condução individual precisava ser guiada, o que muitas vezes ofuscava o que já se via como natural do indivíduo ao que se denominaria direito.

Um segundo ponto, permite destacar que nesse nível de temporalidade, pouco se havia definido ao que se chamara de direitos políticos e socias desenvolvidos nos países centrais no auge do progresso do sistema capitalista no século XIX. Contudo, os direitos civis já se mostravam minimamente postos desde os Estados modernos de Locke (1689) a Montesquiau (1748), e a evolução de tais Estados transcorreu um caminho conturbado na seara do que Marx postulou como "luta de classes" e que criou e estabeleceu suas próprias formas na consideração do que seria cidadania.

Este conceito surge arraigado no estabelecimento de uma forma de sociedade que cada vez mais, mesmo ao tempo da publicização da chamada cidadania, se distanciava dos sujeitos entre aqueles detentores do capital e aqueles detentores apenas da força do trabalho. Para Barbalet (1989), este conceito se estabelece numa sociedade dividida por condições de desigualdade:

\begin{abstract}
A cidadania é manifestadamente uma questão política, mas, no entanto, surgem da sua prática dois problemas de caráter geral demonstrativos de uma apreciação apenas da sua dimensão política. O problema de quem pode exercer a cidadania e em que termos não é apenas uma questão do âmbito legal da cidadania e da natureza formal dos direitos que ela implica. É também uma questão de capacidades não-políticas dos cidadãos derivadas dos recursos sociais que eles dominam e a que têm acesso. Um sistema político com igualdade de cidadania é na verdade menos do que igualitário se faz parte de uma sociedade dividida por condições de desigualdade. (BARBALET, 1989, p. 101).
\end{abstract}

Marx (1890), ao descrever aspectos primordiais da chamada "Acumulação Primitiva" no livro 1, volume II de O Capital, destaca que esta provocou o lançamento do proletariado no mercado de trabalho sem direitos básicos. Na sua acepção, a classe trabalhadora, especialmente a inglesa, foi lançada da idade do ouro para a idade do ferro.

Nesse sentido, tal transição causou desestabilização dos próprios legisladores, que ainda não tinham chegado ao nível de civilização na qual a riqueza nacional, a formação do capital, a exploração impiedosa e o empobrecimento da massa popular, constituía a última 
razão da sabedoria política, principalmente com holofotes centralizados no campo de direitos que até então se exigiria.

Ao navegarmos no tempo, após consolidação de ações em busca da garantia estrutural do Estado, e repousando, mas com ausência de uma devida reflexão histórica nas ideias de Marshall (1967) sobre a cidadania no Estado moderno, encontraremos um claro caminho percorrido para o seu estabelecimento a partir dos direitos proporcionados pelo Estado capitalista.

Acrescentando como um terceiro momento às interpretações anteriores sobre a formação do conceito de cidadania, é conveniente afirmar que essa surge do conflito de classes. Os posicionamentos de Marshall (1967) são bem claros ao mencionar que a cidadania surge a partir das relações estabelecidas com o aparecimento das instituições da propriedade privada. Porém, não descarta o surgimento da cidadania como um estímulo, tanto pela luta em obter direitos, como pelo seu uso depois de obtido, como pontua Barbalet (1989).

Para Marshall (1967), o desenvolvimento da cidadania e do sistema de classes se organiza pela relação antagônica existente, e que no ganho de terreno dentro desse espaço, se modificam. Em sua análise, o Estado é obrigado a garantir os direitos que se vê crescendo na necessidade de inserção da classe trabalhadora. A eles são destinadas as capacidades de atuação na coletividade, ao mesmo tempo, porém, destaca que os direitos civis surgidos são também necessários à munutenção da ordem vigente.

Se é possível fazer uma afirmativa, esta seria associda à ideia de que os direitos de cidadania, apesar de se assentarem numa democracia que tem sido dominante na formação dos Estado, é um apaziguamento das relações conflituosas entre o Estado e o proletariado, ou seja, é no conflito e no ganho de posições nas relações de mercado e classe existentes, que os direitos são requisitados e oferecidos.

Em certa medida, é uma troca de favores para a manutenção de uma conformação que seja favorável ao sistema. Igualmente, essas afrmativas precisam de um certo grau de desconto, já que a evolução dos direitos também contribuiu para a ampliação do espaço de atuação dos menos favorecidos na então sociedade emergente.

Um dos direitos centrais para essa reflexão é o civil, este é caracterizado como o pontapé inicial de toda a possibilidade de garantia possível no Estado moderno por consuetudinariamente o direito da liberdade e de expressão no uso pela coletividade. Para Marshall (1967), o seu uso é uma forma de poder.

A partir do acirramento entre a clase operária e os detentores do capital, especialmente com o advento do sindicalismo como espaços de reivindicações, o aspecto do social vai se consolidando no sentido de se sobrepor às necessidades dessa classe, o que se viu 
a partir daí foi um reconhecimento da capacidade para atuação no Estado, a partir de uma ótica legal, normativa e cidadã.

Para Araújo (2007), e à luz do crescimento dos conceitos e seus pormenores direitos decorrentes, em meados do século XVIII, a transformação no que diz respeito à questão social se fez presente. À ideia do Estado protetor foi somada a de um Estado educador, era preciso uma regeneração da sociedade para os desafios de crescimento que se apresentavam.

O Estado, nesse sentido, obrigou-se a atuar, por meios de serviços, para garantir os direitos socias decorrentes da participação civil e política do cidadão, e uma das necessidades de serviço era a educação.

Os direitos são importantes para a análise social não porque estruturam as relações sociais - se o fazem, fazem-no de maneira incompleta - mas porque as pessoas lutam para alcançar e defender os direitos que julgam proporcionar um mínimo de oportunidades e portanto condições de existência social, e porque os direitos estão associados não só ao status social, mas também às instituições sociais que são o cerne da estrutura social. São estas instituições que têm relações imperfeitas com os direitos que parecem estruturar as relações sociais. (BARBALET, 1989, p. 57).

A educação é apontada como um objeto apropridado de ação por parte do Estado, é um serviço de um tipo único como destaca Marshall (1967). Para ele, a educação das crianças está diretamente relacionada com a cidadania, especialmente no âmbito do direito social, e quando o Estado, a partir das pressões de classes pelo cumprimento de serviços, garante que todas as crianças serão educadas, este tem em mente as responsabilidades sobre as exigências e natureza da cidadania.

Para este autor, é clara a classificação da educação como direito social genuíno, pois o objetivo é o de educar para moldar o adulto em perspectiva, e que o direito não está na criança em ser educada, mas do adulto em ser educado.

A evolução paulatina do termo cidadania, sustetando pelo "tripé" de direitos, é uma expressão do contexto de formação da sociedade capitalista moderna, a pressão social, principalmente oriundas das classes consideradas mais baixas e detentoras apenas da força de trabalho, fez com que ao Estado fosse posta a responsabilidade sobre os acontecimentos provocados pela acumulação produtiva.

Assim, ao mesmo tempo em que se propõe a realizar isso, cria mecanismos de manutenção de discurso que tem a educação como uma das grandes vias de possibilidade, dado seu uso como instrumento de manutenção do status quo.

Muito mais que um direito social na cidadania, a educação é um de seus passos mais importantes, prova disso está na afirmação de Marshall em Citizenship and Social Classe 
(1967) quando destaca que a democracia política necessitava de um eleitorado educado, e de que a produção científica se ressentia de técnicos e trabalhadores qualificados para o modo de produção capitalista.

A educação acompanha as transformações no âmbito da cidadania, especialmente como direito a partir do momento em que é vista como um campo de disputa que amplia espaços de participação de classes no processo, bem como no momento que passa a ser também um mecanismo de apaziguamento de conflitos quando se torna instrumento de alcance, pelos indivíduos, das etapas de inserção no Estado capitalista ao ser utilizada enquanto chave para abertura de portas no mercado de trabalho.

A grande barreira nessa promoção e necessidade da educação estava alocada na própria gênese de constituição do Estado nacional. Liberal por natureza impostiva, promover a educação necessitava a superação do movimento iluminista que negava o seu caráter público enraizado, talvez, até mesmo em sua oposição ao Estado absolutista que tornava, como pontua Araújo (2007), pouco aceitável a ideia deste Estado garantir a instrução das novas gerações sobre as suas "asas".

Poucos negariam, como bem afirmou Mészaros (2007), que a educação e os processos de reprodução mais amplos não estejam intimamente ligados. Uma reformulação signifitiva da educação à luz de uma classificação da cidadania para além de sua relação com o Estado moderno e suas conformações, se isso é possível, seria inconcebível sem a correspondente transformação do quadro social na qual as práticas educacionais da sociedade deve realizar as suas vitais e historicamente importantes funções de mudança.

$\mathrm{Na}$ esteira dessa evolução da cidadania, e seus direitos, e o novo papel a ser desempenhado pelo Estado na sua propositura à luz de seus interesses, Bruno (2011) destaca que a relação entre a educação e o desenvolvimento econômico de forma alguma é linear como se entende em relação à evolução do conceito de cidadania posto pela sociologia inglesa.

Marx (1890), ao analisar a circulação e a reprodução do capital no volume II de sua obra $O$ capital, nos mostra como que entender a educação necessita compreender a reprodução das classes sociais. No tocante à classe trabalhadora, significaria reproduzir as condições de trabalhar não só os que estariam na ativa, mas na manutenção do exército de reserva e na produção das novas gerações e manutenção do circuito do capital.

A dúvida que subjaz nessas colocações é o porquê dessas relações. A resposta em certa medida pode ser considerada como simples, pois foram se conformando historicamente aos passos da constituição dos Estados nacionais, onde a centralidade do grande Leviatã surgiria para a concretização dos aspectos normativos e do contrato social do indivíduo com o Estado, seu guardião e seu promotor. 
A evolução do termo cidadania daí decorre juntamente com seus direitos. Não há como negar a relação que ele proporciona para o surgimento do direito à educação como direito social, especialmente vinculado a necessidade de manutenção da ordem capitalista.

Saltando aos olhos do tempo, mas considerando cada acontecimento, é relevante observar como este processo foi desencadeado no Brasil, especialmente assentado no contexto de mudanças do Estado no início do século XX, cujo o conceito de direito se desenvolve sob caros preceitos como o do estabelecimento de políticas públicas participativas.

\section{Direito Social e a educação no Brasil: uma similitude distinta}

À luz das considerações lineares ${ }^{6}$ da sociologia inglesa sobre o termo cidadania, principalmente sustentadas pelas análises de T.H. Marshall (1950), é importante destacar como esse termo desembarca no Brasil alocado principalmente no entendimento dos direitos sociais como uma de suas decorrências. Para tanto, optou-se em considerar os momentos finais da República Velha (1889-1930) e início da Era Vargas (1930), como de transição para a definição deste conceito, mas que não o esgota.

A saída do Brasil agrícola consolidada pelo processo da Revolução de 1930, é marcada por uma mudança estrutural no país, as autonomias das oligarquias estaduais agora precisariam responder ao crescimento do estado centralizador e controlador das funções institucionais. O fato que caracteriza essa transição está assentado no processo de industrialização e de suas novas formas de providência para o conjunto da população a partir das garantias do Estado.

O rápido movimento de constituição do aparelho econômico do Estado entre 1930 e 1945, em sua forma centralizadora e nacionalmente articulada, à luz da superação das autonomias estaduais do período oligárquico do café com leite, obedece a um padrão cujas características nem sempre foram enfatizadas pela extensa literatura existente, enfatiza Draibe (1985).

Nessa etapa crucial de constituição do “capitalismo industrial” no Brasil, condensamse num curto período histórico, as múltiplas faces de um processo de organização das estruturas de um Estado-nação capitalista cuja forma incorpora, crescentemente, aparelhos regulatórios e peculiaridades intervencionistas que estabelecem um suporte ativo ao avanço

\footnotetext{
${ }^{6}$ Gilda Cardoso Araújo, no artigo Estado, Direitos de Cidadania e Direito à Educação: do programa ao diagrama (2007), descreve de forma lúcida a linearidade com que T.H. Marshall faz da "evolução" do termo cidadania na Inglaterra. Em sua análise, os países necessariamente não precisam ter o aspecto da evolução desse termo de forma única e linear como ocorreu na Inglaterra com o surgimento do tripé cronológico da cidadania: direitos civis - direitos políticos - direitos sociais. Cada realidade pode ter sua própria evolução, que necessariamente não precisa estar nessa ordem, caso clássico é o Brasil, que em sua avaliação, teve os direitos sociais crescidos de forma consolidada precedente aos direitos políticos, por exemplo, decorrência em boa medida do próprio desenvolvimento do Estado brasileiro entre as décadas de 1930-1960.
} 
da acumulação industrial, essas alocadas no estabelecimento rápido de instituições e de vultuosas transações em torno do campo financeiro.

O Estado criou uma base jurídica institucional para o funcionamento e integração de mercado de trabalho, e também organizou o próprio sistema de representação classista, levando a extremos econômicos e sociais a sua ação regulatória e intervencionista, acrescenta Draibe (1985).

Diante desse cenário de mudanças, é necessária a reflexão de como se insere a educação como direito social no Brasil, especificamente procurando entender como se estabelecem os interesses de promoção de uma política educacional que a partir de então precisaria responder a outros desafios postos pelo Estado.

O Brasil industrial que presencia a ampliação do conceito de cidadania dos países centrais é marcado por um fortalecimento das instituições oficiais e da sociedade em geral, que posicionados contra o Trust ${ }^{7}$ internacional, precisaram estabelecer uma paz social pela via da defesa do nacional-desenvolvimentismo, que a partir de então estabeleceria necessidade de outra forma de organização educacional.

Uma importante observação está no fato de que no Brasil, devida distinta característica agrária e atraso na estruturação de um corpo industrial, o desenvolvimento do conceito de cidadania se distancia da linearidade proposta pelo socialismo inglês.

A ampliação dos espaços de desenvolvimento do capital industrial necessitaria de concessões pontuais no âmbito social que até então estavam distantes devido ao formato político de concessões e barganhas então existentes, o que pôde corroborar para que o conceito do social na perspectiva cidadã brasileira veio antes da consolidação de espaços políticos, ofuscando a linearidade de desenvolvimento do campo civil, político e social presente no contex to inglês.

No século XIX, quando Marx escreveu sua obra, o tempo de ociosidade que o trabalhador passava fora da fábrica era tão reduzido que não exigia nenhuma dedicação especial sobre a família, o trabalho doméstico ou a educação formal. Todavia, a vitória nas lutas travadas pelos trabalhadores na obtenção da fixação/redução da jornada de trabalho e melhores salários deu uma nova tonalidade às políticas publicas de educação. (BRUNO, 2011). Encontramos em Marx (1890) dois pontos fundamentais pela qual se associam as intencionalidades da educação no Brasil no começo do século XX para o elo cidadania e direito social, principalmente, pela forma adquirida no desenvolvimento do capitalismo industrial do país.

\footnotetext{
${ }^{7}$ Grupos que, sob uma mesma orientação, mas sem perder a autonomia, se reúnem com o objetivo de dominar o mercado e suprimir a livre concorrência e também são grandes grupos ou empresas que controlam todas as etapas da produção, desde a retirada de matéria-prima da natureza até a distribuição das mercadorias.
} 
O primeiro deles está no que ele compreendeu sobre os processos de produções da mais valia absoluta e da mais valia relativa, e que assim, poderá ser interpretada sobre ações da educação. A natureza de cada forma no processo de trabalho ajuda a entender onde se posiciona a educação enquanto resposta. Para Marx (1890),

a produção da mais valia absoluta se realiza com o prolongamento da jornada de trabalho além do ponto em que o trabalhador produz apenas ao equivalente ao valor de sua força de trabalho com a apropriação pelo capital desse trabalho excedente. Ela constitui o fundamento do sistema capitalista e o ponto de partida da produção da mais valia relativa. Esta pressupõe que a jornada de trabalho já esteja dividida em duas partes: trabalho necessário e trabalho excedente. Para prolongar o trabalho excedente, encurta-se o trabalho necessário com métodos que permitem produzir-se em menos tempo o equivalente ao salário. A produção da mais valia absoluta gira exclusivamente em torno da duração da jornada de trabalho; a produção da mais valia relativa revoluciona totalmente os processos técnicos de trabalho e as combinações sociais (1980, p. 11. grifos nossos)

Bruno (2011) acrescenta que, na mais-valia relativa o aumento do tempo de trabalho excedente resulta da passagem do trabalho simples para o trabalho complexo ${ }^{8}$. Para o capitalismo industrial brasileiro a complexidade estava associada ao incremento de formas maquinárias de desenvolvimento das atividades. Para tanto, requeriu reformas nas políticas educacionais da época incidindo uma preocupação na garantia da educação como direito social aproximado das demandas impostas pelo novo formato social.

$\mathrm{O}$ conjunto das relações sociais tem o trabalho como uma de suas peças, todo o processo estabelecido socialmente se expressa de forma que a educação é um meio para o fortalecimento das relações, principalmente as que contém interesses de uso e de troca imbricados. No caso da expressão da mais valia absoluta e relativa, o entendimento nos leva a perceber que a educação incidida no trabalho contribuiria para a melhoria dos elementos que as definem conceitualmente.

Um segundo fator relevante para a discussão está na compreensão da educação como valor de uso e valor de troca. Com as mudanças na cadeia produtiva, a questão da qualificação passou a ser fator fundamental.

De acordo com Bruno (2011), a qualificação se classifica como um estrutura cujos elementos se apresentam hierarquizados entre si a partir de uma determinada lógica, que por sua vez é dada pelas relações sociais vigentes. Historicamente no capitalistmo, a qualificação

\footnotetext{
${ }^{8}$ Para Adriana Melo, André Martins, Camila Souza, Ialê Falleiros e Lúcia Neves no livro (2015) Educação Básica: tragédia anunciada?, que está organizado em conjunto de trabalhados de outros pesquisadores em educação, há elementos teórico-metodológicos e históricos que caracterizam as mudanças nas políticas de educação básica na atualidade, são eles: i) redefinição da formação para o trabalho simples no mundo capitalista; ii) as mudanças na estrutura e na dinâmica do capitalistmo neoliberal mundial; iii) bem como as repercussões no estabelecimento das diretrizes e bases da escolarização básica.
} 
diz respeito à capacidade do trabalhador de realizar as tarefas requeridas pela tecnologia utilizada, o que exigiria o desenvolvimento manual e intelectual; sobre este último é que se configura o novo formato da educação.

Estar qualificado significa promover uma capacidade de trabalho passível de ser utilizada na produção do valor. Para o capitalista, ao estar mais qualificado o trabalhador se torna apto ao melhor desempenho, o que faz com que o coloque como valor de uso pelo capitalista. De certa maneira, essa nova configuração se apresenta no Brasil quando da passagem do Estado agrário para o industrial, já que era necessária a expansão desse lócus por meio de um melhor desempenho pelo proletariado então surgido, claro, guardadas as devidas singularidades da época.

Ao trabalhador lhe é atribuído o valor de troca, pois pela educação poderia ser agregada a qualificação desse valor a ser vendido ao capitalista. Nesse sentido, o Estado, associado às concepções do capital necessitava ampliar seu posicionamento sobre o quesito educação da sua massa de trabalhadores, fato que se mostra claro desde a Era Vargas com o incremento da indústria na economia.

Fato é que este ideário de valor de uso e de troca amplia-se nos dias atuais, contudo, nos seus primórdios é que se estabeleceram as bases de interesses sobre a educação como instrumento que ratificaria essa intencionalidade.

A recuperação histórica permite acompanhar que a cidadania e o direito social à educação passam a existir pautados numa necessidade de resposta do Estado econômico que surgira; à educação, furta-se o momento em que é pautada como um direito social voltado para a concepção de formação humana, caracterizando-se pela preparação ao mercado de trabalho, no que se evidencia a troca que o Estado realiza com o indivíduo, trabalhar de forma qualificada para o desenvolvimento favorável do capital e, assim se garantirá os direitos mínimos para a sobrevivência.

O social está totalmente vinculado aos desejos necessários do sistema financeiro, não há uma perspectiva sociológica que supere os elementos de conformação do capital sobre a educação, assim foi com o advento do capitalismo industrial no Brasil até os dias atuais.

Retomando Bruno (2011), esta permite uma visualização sobre qual campo se deu a evolução do conceito de cidadania. Em seu entendimento, em termos históricos, e em linhas gerais, desde que o capitalismo começou a desenvolver-se,

a capacidade de trabalho do proletariado foi se caracterizando pela seguinte sucessão: inicialmente a qualificação dizia respeito à capacidade de realizar operações que exigiam grande esforço físico e habilidades manuais sempre mais aprimoradas; depois, progressivamente, enquanto era obtido esse crescente adestramento muscular e manual, foram sendo desenvolvidos os 
componentes intelectuais da qualificação dos trabalhadores. Atualmente, a etapa que estamos começando a atravessar caracteriza-se exatamente pela predominância dos componentes intelectuais da força de trabalho, especialmente daquela em processo de formação. (BRUNO, 2011, p. 72).

Destacar esses pontos históricos vai de encontro à afirmativa de que eles começam a se desenvolver no Estado capitalista industrial no Brasil. A educação como direito social é proveniente de um desenvolvimento do conceito de cidadania a partir das necessidades do Estado em sua organização para o econômico, todas as alternativas de crescimento da oferta da educação estiveram pautadas em responder as demandas impostas.

\section{Educação: direito ou interesse?}

O campo da educação sinaliza e solicita atenção especial para uma nova dinâmica no momento em que a cidadania enfrenta novos desafios buscando outros espaços de atuação e paradigmas de representação diante das grandes transformações pelas quais passa o mundo contemporâneo, segundo Cury (2002).

Cabe propalar no debate que tal conceito esteve circunstanciado pelo o que se entende por garantia de direitos no Estado constitucional, e de como este pode corroborar para o desenvolvimento de políticas públicas voltadas para o apaziguamento dos ânimos sociais. Nesse contexto, é válido publicizar a ideia de Frey (2000) de que a constelação de forças sociais e políticas em prol do exercício do poder pelas elites políticas e econômicas no caso brasileiro, determinam de forma decisiva os rumos do País do que quaisquer outros arranjos, independentemente de quão institucionalizados.

Nesta perspectiva, Azevedo (2002), chama atenção para o fato de que os direitos não estão no abstrato, são complexidades intrincadas em uma totalidade que, só se concretizam no momento em que indivíduos ou grupos os exigem, ou, em que, no mínimo, se possa supor que as pessoas que deveriam exigí-los tenham consciência de sua falta, ou seja, os direitos fazem parte de uma síntese que tem marcas profundas nas relações sociais e disputas de classes.

$\mathrm{Na}$ formalidade, a constituição do império brasileiro (Constituição de 1834) já propunha em seu artigo n. 179 a instrução primária e gratuita, bem como os colégios e universidades onde seriam ensinados os elementos das ciências, belas-artes e letras. Na visão de Bobbio (1986), a gênese histórica de um direito começa como uma exigência social que vai se afirmando até se converter em direito positivo.

Nesse sentido, Cury (2002), destaca que a conversão ao direito positivo não significa a univesalização do mesmo, mas de seu alcance. $\mathrm{O}$ momento indica que a exigência se torna 
generalizada para todos os cidadãos ou amplia os níveis de atendimento quando esta é resultado de um conflito sobreposto ao sistema.

A declaração do direito à educação é recente, data do final do século XIX e, carrega em si uma distinção totalmente associada à evolução do Estado capitalista. Para tanto, o direito não é de forma alguma independente do jogo das forças sociais em conflito, seja na origem, no seu estabelecimento ou manutenção. Para fazer uso desta ferramenta tão importante na sociedade moderna, é necessário o reconhecimento de que o direito a educação não poderá prescindir de sua atualidade, muito menos do seu entendimento pela constituição.

Não são poucos os documentos de caráter internacional que ratificam o direito de acesso a seus cidadãos, como consta no art. XXVI da Declaração Universal dos Direitos do Homem, de 1948; no texto da Convenção Relativa à Luta contra a Discriminação no Campo do Ensino, de 1960; no art. 13 do Pacto Internacional dos Direitos Econômicos, Sociais e Culturais, de 1966 e, mais recentemente, na Declaração Mundial sobre Educação para todos, Conferência de Jontien ${ }^{9}$, de 1990.

A existência de um direito seja em sentido forte ou fraco, implica sempre a existência de um sistema normativo, onde por "existência" deve entender-se tanto o mero fator exterior de um direito histórico ou vigente quanto reconhecimento de um conjunto de normas como guia da própria ação. A figura do direito tem como correlato a figura da obrigação (BOBBIO,1986, p. 87).

Apesar do reconhecimento expresso em documentos chancelados internacionalmente, é necessária uma garantia de cumprimento inclusive em âmbito nacional. Contudo, há uma dificuldade de instaurar um regime na qual a igualdade política aconteça no sentido de diminuir as distorções, devida em grande parte à incapacidade administrativa dos governos na expansão da oferta perante a ordem jurídica que se acomete do atendimento das demandas de interesses de classe, muito mais do que a permissão ao acesso do direito de fato. Desta forma, a legislação tende a antecipar o desenvolvimento contextualizado da condição social, nasce assim do caráter contraditório em uma dimensão de luta.

Para Cury (2002), a história do direito à educação é semelhante a luta por uma legislação protetora dos trabalhadores na indústria nascente, pois em ambos os casos, foi no século XIX que se lançaram as bases para os direitos sociais como integrantes da cidadania.

\footnotetext{
${ }_{9}^{9}$ A Conferência de Jomtien, Tailândia, realizada em 1990, ratificou que a educação não é apenas um direito, mas também a chave de todo o desenvolvimento. Por isso, fixou seis metas essenciais: I - expansão da assistência e das atividades de desenvolvimento da primeira infância, especialmente para as crianças pobres; II - acesso universal à educação primária e sua conclusão até o ano 2000; III - melhoria dos resultados do aprendizado de modo que a percentagem acordada de uma mostra de idade determinada alcance em nível dado: IV - redução da taxa de analfabetismo dos adultos à metade daquela de 1990 no ano de 2000, com ênfase na alfabetização feminina: V - ampliação dos serviços de educação básica e de capacitação para jovens e adultos e; VI - aumento da aquisição pelos indivíduos dos conhecimentos, das capacidades e dos valores necessários para viverem melhor e conseguirem um desenvolvimento sustentável (UNICEF, 1993).
} 
É composto por um "direito de múltiplas faces” ao mesmo tempo social, econômico e cultural; social por promover o pleno desenvolvimento da personalidade humana; econômico por favorecer a auto-suficiência por meio do emprego ou do trabaho autônomo; e cultural no sentido de se inserir na construção de uma cultura universal de direitos humanos. Contudo, as desigualdades colocam barreiras à afirmação do primado do direito à educação que tenha essas vias como caminho seguro de trânsito.

Diferentemente dos países industrializados, os ditos periféricos do capitalismo, em especial, os países latinoamericanos, não contaram com a formação de uma forte classe operária, quem dirá ter fortes condições iniciais para exigir uma educação à luz das perspectivas de direitos sociais nascidas nos países centrais do capitalismo.

Para Cury (2002), a escravidão, o desqualificador caráter agrário-exportador desses países, e uma visão preconceituosa em relação ao próximo, determinaram uma estratificação social com características hierárquicas colocando, por meio das classes dominantes, um sentido diferente à educação das camadas populares, pouco mais que a cultura oral para mantê-as subalternas.

A leitura e interpretação de livros em geral, ou dos livros sagrados eram
reservadas aos bacharéis e aos teólogos, autorizados pela Igreja Católica.
Daí porque a transmissão oral ganha relevância sobre a transmissão
baseada no acesso à leitura e à escrita a todos. Tal tradição se opõe à
experiência européia dos paises que conheceram a Reforma. Neles, a tese
luterana da sola fide scriptura implicou não só o desenvolvimento da
imprensa como também o incentivo a que todos os fiéis, mediante a
instrução, pudessem ler os livros sacros e meditar sobre a palavra de deus.
Por isso, nestes países colonizados será longa e árdua a luta pelo direito à
educação em geral (CURY, 2002, p. 87).

Sob este prisma, a elite que pagava a escola de seus filhos não entendia a necessidade da expansão e garantia pelo Estado do ensino público aos seus cidadãos, o que de certa forma se postava na contramão até mesmo da concepção de cidadania apregoado pelos países centrais do capitalismo no que tange à garantia de direitos e acesso a serviço do então Estado que se constituía.

Nas palavras de Estevão (2007), o direito a educação tende a reduzir-se a quantidade e a modernização, fugindo de seu compromisso in natura com a democratização participativa, o que é pior e, de certa forma, ruim para sua concepção. Ademais, chegaríamos a uma escolarização que valoriza os números e suas metas, desconsiderando uma agenda de emancipação política, ou pior ainda, não pondo a emancipação humana como ponto de chegada.

A educação deve buscar a procura pelo horizonte e caminho da ética e da justiça, necessita ser desejada, o que Estevão (2007) denominou de um processo de solidariedade 
cordial, de amorização, de condenação da exploração e do sofrimento, de fidelidade às pessoas e celebração da amizade, no qual o direito à igualdade e à diferença sejam articulados.

Não restam dúvidas de que a educação se constitui enquanto sujeito principal do processo de construção e afirmação da democracia como modo de organização social e político. É um relevante requisito para que sejam acionados e consolidados canais de participação, de modo que seja garantido o exercício dos direitos políticos e sociais.

De toda a forma, as conquistas em âmbito jurídio legal do direito à educação demonstram para Mendonça (2000), que há um certo grau de atraso na democratização da educação no país, simplesmente pela demora em incorporar a educação como direito de todos e todas, e não apenas à serventia de qualificação para o trabalho simples.

Os anos de luta desde o Manifesto dos Pioneiros ${ }^{10}$ permitem que nos postemos nos dias de hoje empunhando bandeiras sociais superadas por países mais avançados como universalização do ensino básico, e consequente ampliação da rede física escolar, distribuição do material e garantia de alimento escolar, valorização do seu quadro de docentes, dentre outras ações que se veem cada vez mais ancoradas no pano de fundo por discursos que expõem o conceito de educação à mera prestação de serviços para quem dispõe de condições econômicas para obtê-la.

Historicamente, a evolução conceitual sobre a importância da educação no Brasil é recente, somente nos anos 1930 surgem, a partir da ascensão de Getúlio Vargas ao poder, as primeiras preocupações sobre a importância da educação na constituição e desenvolvimento do Estado. Saindo de uma formação agrária, se vislumbrava com ela o caminho rumo às mudanças estruturais que eram necessárias, especialmente as associadas ao modo de crescimento econômico.

Nesse tempo, o manifesto dos pioneiros teve um importante papel por apontar os anseios em torno de uma educação vista como justa, e de superação das visões centralistas que marcaram profundamente o cenário educacional do país, que de certa forma levaram a um processo de exclusão que se projetou de encontro aos ideais de cidadão que arrolou a educação como um dos elementos de composição e de realização dos direitos socias.

Descentralização da oferta, fortalecimento de políticas educacionais e formação humana se caraterizavam enquanto desejos de uma nova visão de educação que fosse capaz de se afastar das necessidades do Estado, e passasse a se aproximar dos anseios de formação para exercício da cidadania.

${ }^{10} \mathrm{O}$ "Manifesto dos Pioneiros da Educação Nova" consolidava a visão de um segmento da elite intelectual que, embora com diferentes posições ideológicas, vislumbrava a possibilidade de interferir na organização da sociedade brasileira do ponto de vista da educação. Redigido por Fernando de Azevedo, o texto foi assinado por 26 intelectuais em 1922. 
Após reformas normativas e, principalmente, ideológicas, o que se percebe no Brasil é o não cumprimento, na totalidade, do quesito educação como direito social. Passadas décadas, o país não foi capaz de proporcionar todas as benesses da educação, especialmente aquelas associadas à inclusão de todos no processo formal de ensino.

Ao contrário, o que se evidencia é um profundo vínculo da educação como instrumento de validação dos ideários dos países centrais na criação do corpo ideológico e a favor dos interesses do capital. A preparação para o trabalho simples, ao contrário da busca pela emancipação política e humana, ainda se constitue como um dos grandes empecilhos da garantia ao direito. No momento ele se concretiza como proposta de inserção numa cidadania pautada na conformação da cessão via conflito de classes muito mais do que qualquer outra reflexão de formação social.

Esse cenário foi campo fértil para as diferentes reformas educacionais ocorridas no Brasil desde o Estado Novo, ditadura militar e a chamada reabertura democrática. Tais reformas estiveram como viés a colaboração externa nos rumos da educação, principalmente no que se refere a menos garantia de acesso.

Necessita-se de uma atenção para que a consolidação do grau democrático leve em conta, sobretudo a cultura política e adminstrativa, que são responsáveis pela configuração específica das estruturas, dos processos e funções da sociedade, para que as postergações rumo a um tipo de educação excludente não se sustente sob uma lógica de camuflagem de benesses inexistentes, mas fantasiosas e incisivas no estabelecimento e consolidação de interesses enraizados desde a base de formação da sociedade brasileira.

Disso, resulta a observação sobre o que assinala Oliveira (2005), de que o Estado social ao selecionar o tipo de política pública para a sua agenda, uma espécie de tomada de decisão no ciclo da polítia pública, traduz em normas jurídicas as suas decisões sobre seus cidadãos, uma vinculação de reponsabilidade que deve ser amparada subsequentemente pelo campo do direito.

Assim, pensar numa educação como direito social, cujo pano de fundo seja a sua serventia para o processo de emancipação histórica do sujeito, é um desafio que está posto de forma provocativa quando circunscrito nos dias atuais pela a inserção de uma lógica mercadológica e da eficiência propalada pelos ditames de uma Nova Gestão Pública.

O grau evolutivo das sociedades modernas exige a ótica de salvaguarda do direito, principalmente no tocante ao estabelecimento e cumprimento da demanda, e a educação se conforma com uma das destacáveis requerentes tendo em vista seu relevante papel de constituição social. Seja pela via da política pública, do processo de reconhecimento de demandas específicas ou da judicialização das decisões, convém, sob olhar pessoal, o entendimento de que os aspectos de disputa de classe devem ser considerados para fins de 
debates em quasiquer esferas. A relação Estado, cidadania, direito e educação são nós pontuais na estruturação da sociedade atual.

Desde meados das décadas de 80 e 90 , o que se percebe é um afunilamento das intencionlidades de uma educação pública subjulgada para além de sua caracterização histórica, pelos anseios de uma educação que tenha seu escopo amparado pelo eficiencicismo que de uma forma ou de outra, descaracteriza ainda mais as necessidades sociais em prol do acesso e permanência numa educação cujo espelho seja o da emancipação humana.

A lógica privatista tem substituido o do coronelismo e do paternalismo de classe, conformando assim uma outra forma de exclusão que coloca em risco as reais possibilidades de uma educação justa tanto no acesso, quanto na oportunidade.

Com o processo de implantação da NGP, como alternativa ao chamado declínio da burocracia weberiana, o que se percebe é um total enxugamento do vislumbramento de uma educação mais democrática como prevista na Consituição Federal de 1988.

A gestão da escola como uma complexa categoria político-educativa, de construção social que não dispensa os contextos históricos, os projetos políticos e a correlação de força, se vê cada vez mais substituída por conceitos ao participacionismo, empowerment, o enxugamento, incrementos de avalição em larga escala e o trabalho em equipe como sinônimo de internalização dos objetivos do negócio.

Não se pode perder de vista que essa evolução acompanha todo o percurso histórico vivenciado pela educação brasileira, especialmente quando entra na rota da nova reconfiguração adminsitrativa que em boa medida põe em cheque, ou acentua os riscos da garantia do direito à educação.

De uma história já viciada pelos desmandos do percurso educacional brasileiro, sinaliza-se para um amplo processo de esfacelamento das experiências alternativas de gestão pública com o advento da lógica assentada na NGP que subjaz o conceito de formação humana para o de prestação de serviços cujo pano de fundo está na lucratividade. Cabe sinalizar que a inscrição da educação como diereito social esteve alocado na perspectiva do público no Estado brasileiro, apesar de todas as normativas e indicações históricas sobre o seu valor como bem público, a educação nos dias atuais tem como interesses as demandas privatisitas, especialmente que a veêm como espaço promissior de lucro.

O que se adventa no Brasil já não é mais apenas a formação do trabalhador em habilidades necessárias ao mercado de trabalho, e a educação pública nesse caso desempenhou importante função, mas, para além disso, são necessários que as raízes do que seja educação esteja amparada pela lógica do mercado, e dela se extraiam todas as benesses. 
Estudos de Newman e Clarke (2012) acentuam que há gritantes fatores de declínio das noções do público e do setor público, que agora tem sido suejto a processos renovados de framentação e mercantilização, o que, invarialmente, acerta de cheio às perpecetivas de interesse da educação como direito.

\section{Considerações e notas}

Desde o advento da sociedade capitalista forja-se a inópia da formação como item chave para o sucesso de acumulação, mesmo que em certos momentos da história isso não tenha sido posto de forma tão clara, os elementos constituintes têm sido fortalecidos pelo movimento do capital em conflito com a órbita das garantias normativas e de direito.

O desenvolvimento da cidadania no Brasil seguiu a lógica de obediência aos ditames do capitalismo, e por aí foram estabelecidas as políticas educacionais no país. A entrada do capitalismo industrial, a partir do ideário de nacional-desenvolvimentista da década de 1930, posicionou a educação como direito social no caminho da formação do trabalhador.

As preocupações alocadas na educação estiveram alheias a uma oferta inclusiva até a nova República, quando normativamente na Constituição Federal de 1988 foram então prescritos conceitos de cunho mais democrático, mas ainda assolados pelas incursões mercadológicas dos países centrais.

O que se oberva é que as políticas educacionais estiveram subordinadas a um modelo econômico que encobriu com um véu o quadro sombrio e excludente que expõe a debilidade da oferta pública. Os privilégios do Estado sobre as regras da educação almejam inibir que a maioria tenha acesso ao direito à educação, o que torna o conceito cidadania e o direito social um mero aporte instrumental do Estado capitalista, especialmente ancorados numa qualificação para a mais valia e o valor de uso.

Em tempo, falar de educação enquanto direito social nos dias atuais remete a refletir sobre o seu papel desempenhado, não há como afirmá-lo apenas pelo olhar da formação para o mercado de trabalho, ou como um item a ser garantido pelo poder normativo e de interpretação jurídica constitucional. A forma de inserção da educação no Brasil acompanhou o processo de evolução econômica do Estado, contudo ainda insiste em acompanhar a evolução de tal conceito que não se desprende das reais funcionalidades do sistema.

A inscrição da educação como direito social no Brasil percorreu um longo percurso apesar do curto tempo disponível. Mas, não há dúvidas na afirmativa de que ela esteve cerceada por uma nova configuração de sociedade que exige o fornecimento de atributos gerais que garantam a apreensão de qualificações específicas. 
A educação historicamente tem sido marcada por prolongamentos da intencionalidade dos grupos dominantes, instrumentalizada para o alcance da conformação de sociedade que se quer vigente. Apenas ditá-la como direito social por si só, não é garantia de acesso a tal benefício, pelo contrário, pode, nesse exato momento de uma conceituação justa para impor aspectos falaciosos sobre a educação.

Estamos acostumados a nos calar diante da rubricas normativas de que a educação é um direito, contudo, há ainda muitos caminhos a serem trilhados para que este direito seja de fato ratificado como o entendimento do papel da intepretação jurídica, de como são criadas e gestionadas as politicas públicas, bem como se permite, via Estado, a garantia do direito como um instrumento de uma norma favorável ao engrandecimento da cultura social coaduna com a moral da justiça igualitária para todos.

Desse cenário, reafirma-se a necessidade que se deve pôr em vistas de uma educação ancorada no campo do direito para além do aspecto jurídico e normativo, mas prático. $\mathrm{Na}$ atual configuração vemos um crescente movimento que sinaliza uma ampliação dos interesses do capital a um direito vinculado às suas necessidades, convindo a afirmar que, nos dias atuais, ele somente se transmutou para a atualidade, mas que desde sempre se fez presente na história da educação brasileira.

O que se entende por "história viciada" está na reflexão de que a educação na conformação do Estado brasileiro foi abdicada de seus sentidos para hora e outra servir a interesses escusos da sociedade dominante amparada pelo Estado burguês. De então, chegase no século XXI sendo vítima de mais uma manobra ideológica que agora a põe como um benéfico espaço de lucro para o capital especulativo, perdendo assim o seu valor como lócus de formação humana socialmente referenciada.

\section{Referências}

ARAÚJO, Gilda. C. Estado, direitos de cidadania e direito à educação: do programa ao diagrama. 30 Reunião da Anped, Caxambú, 2007.

AZEvEDO, Antônio Junqueira. Caracterização Jurídica da Dignidade da Pessoa Humana. Revista da Faculdade de Direito da Universidade de São Paulo, 2002. Disponível em: http://www.revistas.usp.br/rfdusp/article/view/67536. Acesso em: Nov de 2019. DOI: https://doi.org/10.11606/issn.2318-8235.v97iop107-125

BARBALET, J. M. A cidadania. Lisboa: Estampa, 1989.

BOBBIO, Norberto. O futuro da democracia: uma defesa das regras do jogo. Rio de Janeiro: Paz e Terra, 1986. Doi: https://doi.org/10.1590/s0034-75901986000400010

BRUNO, Lúcia. E. N. B. Educação e desenvolvimento econômico no Brasil. Revista Brasileira de 
Educação. v. 16, n.48, set-dez. 2011. DOI: https://doi.org/10.1590/s1413-24782011000300002

CURY, Carlos R. J. O direito a educação: um campo de atuação do gestor educacional na escola. MEC - Secretaria de Educação Básica - Brasília, 2006.

CURY, Carlos R. J. Educação e contradição: elementos metodológicos para uma teoria crítica do fenômeno educacional. 2. ${ }^{\text {e }}$ ed. São Paulo: Cortez: Autores Associados, 1986.

CURY, Carlos R. J. O direito à educação: direito à igualdade, direito à diferença. Cadernos de Pesquisa, n. 116, p. 245-262, julho/2002. Disponível em: <http://www.scielo.br/pdf/cp/n116/14405.pdf>. Acesso em: Nov de 2019. DOI: https://doi.org/10.1590/s0100-15742002000200010

DRAIBE, Sônia. Rumos e metamorfoses: um estudo sobre a constituição do Estado e as alternativas da industrialização no Brasil, 1930 - 1960. Rio de Janeiro: Paz e Terra, 1985.

ESTEVÃO, Carlos V. Direito à Educação: Para uma educação amiga e promotora de direitos. Brasília - DF, Coleção Educação para Todos, 2007.

FREY, Klaus. Políticas públicas: um debate conceitual e reflexões referentes à prática da análise de políticas públicas no Brasil. Planejamento e Políticas Públicas: PPP, Brasil, n. 21, p.211-259, jun. 2000. Semestral. Disponível

em: <http://desafios2.ipea.gov.br/ppp/index.php/PPP/article/viewFile/89/158>. Acesso em: Nov de 2019.

LIMA, Licínio C.. A Gestão Democrática das Escolas: do autogoverno à ascensão de uma pósdemocracia gestionária?. Educação e Sociedade., Campinas , v. 35, n. 129, p. 1067-1083, Dec. 2014 . Available from <http://www.scielo.br/scielo.php?script=sci_arttext\&pid=So10173302014000401067\&lng=en\&nrm=iso>. Acesso em: Nov de 2019. DOI: https://doi.org/10.1590/es0101-73302014142170

MARSHAL, Theodore H. Cidadania e classe social. In:. Cidadania, Classe Social e Status, Rio de Janeiro: Zahar, 1967.

MARX, Karl. Crítica do Programa de Gotha. São Paulo: Boitempo Editorial, 2012.

MARX, Karl. O Método da Economia Política. In:. Grundrisse. São Paulo: Boitempo, 2011. pp.53-89.

MARX, Karl. O capital. Rio de Janeiro: Civilização Brasileira, 4ª ed. 1975

MÉSZÁROS, István. A crise estrutural do capital. 2.ed. rev. e ampliada. - São Paulo : Boitempo, 2011.

NEVES, Lúcia M. W. (org). Educação Básica: tragédia anunciada? São Paulo : Xamã, 2015.

Newman \& Clarke. Gerencialismo. Educ. Real., Porto Alegre, v. 37, n. 2, p. 353-381, maio/ago. 2012. Disponível em: http://www.ufrgs.br/edu_realidade. Acesso em: Nov de 2019.

NEWMAN, Janet; CLARKE, John. Gerencialismo. Educ.Real., Porto Alegre, v. 37, n. 2, p. 353381, maio/ago. 2012. Disponíve em: <http://www.ufgrs.br/edu_realidade>. Acesso em: Nov de 2019. http://dx.doi.org/10.1590/2175-623687897

OLIVEIRA, Vanessa Elias. Judiciário e privatizações no Brasil: existe uma judicialização da política? Revista de Ciências Sociais: Rio de Janeiro, v. 48, n. 3, p.559-587, jul./set. 2005. Disponível em: <http://www.scielo.br/pdf/dados/v48n3/a04v48n3.pdf>. Acesso em: 08 jun. 2012. DOI: https://doi.org/10.1590/s0011-52582005000300004

PAUlA, Ana Paula P. de. Por uma nova gestão pública: limites e potencialidades da experiência contemporânea. Rio de Janeiro : Editora FGV, 2005. 204 p. 